\title{
METHOD OF MATERIAL QUALITY ESTIMATION WITH USAGE OF MULTIFRACTAL FORMALISM
}

\author{
Volodymyr VOLCHUK, levgenii KLYMENKO, Sergii KROVIAKOV, Matija OREŠKOVIĆ
}

\begin{abstract}
Feasibility of application of multifractal theory for evaluation of materials mechanical properties, cast iron in particular, has been considered. The proposed method enables evaluation of mechanical properties of materials based on determination of their sensitivity to dimensions of structure elements from the multifractal Renyi spectrum. Sensitivity of cast iron ultimate strength to informational dimension of carbides, ultimate bending strength to fractal dimension of carbides, impact strength to correlation dimension of carbides and hardness to fractal dimension of graphite have been determined. Fractal prediction models of quality characteristics of cast iron based on the analysis of the following its structure elements (carbides and graphite) have been received.
\end{abstract}

Keywords: cast iron; graphite; mechanical properties; sensitivity coefficient; spectrum of Renyi dimensions; theory of multifractals

\section{INTRODUCTION}

Establishing the connection between composition, structure and properties of materials is determined with application of different methods including mathematic simulation. For example, in works $[1,2]$, about the use of multifactor modeling, the residual load-bearing capacity of the damaged reinforced concrete structures is calculated and ways to strengthen them are considered; in [3, 4] the properties of concretes on lightweight porous fillers for thin-walled structures are evaluated.

Many elements of materials structure at different scale levels have a complex geometrical shape configuration which cannot always can be appropriately described by the use of traditional methods. For example, based on analysis of quantitative and qualitative assessment of many ironcarbon alloys of real structures, there are some differences between the results of direct experiments on determination of their qualitative characteristics using predictive methods [5] that must be observed for usage in practical purposes.

This fact represents insufficiency of formal axiomatic which arises during approximation of metal structure elements using the traditional figures of Euclid's geometry; this emphasizes the necessity of usage of the other prospective approaches to its assessment.

Fractal approach is these days successfully used for the structure analysis [6-9]. Particularly, multifractal theory is used for estimation of heterogeneous structures of metals, concretes, polymers and other materials. Having that in mind, here is the proposed method of estimation of quantitative characteristics of different materials based on multifractal analysis of their structure.

\section{MATERIALS AND METHODS}

Cast iron for manufacture of casting roller with spherical form of graphite was used as test material $(0.5 \ldots 2.5 \%)$; its chemical composition is as follows: $3.00 \ldots 3.40 \% \quad \mathrm{C}, \quad 1.45 \ldots 1.80 \% \quad \mathrm{Si}, \quad 0.45 \ldots 0.65 \% \quad \mathrm{Mn}$,
$0.040 \ldots 0.200 \% \quad \mathrm{P}, \quad 0.004 \ldots 0.010 \% \mathrm{~S}, \quad 0.60 \ldots 0.90 \% \mathrm{Cr}$, $0.70 \ldots 1.30 \% \mathrm{Ni}, 0.035 \ldots 0.056 \% \mathrm{Mg}$. Quantity of carbides (cementite, $\mathrm{Fe}_{3} \mathrm{C}$ ) is $20-30 \%$. Figs. 1 and 2 shows cast iron structure.

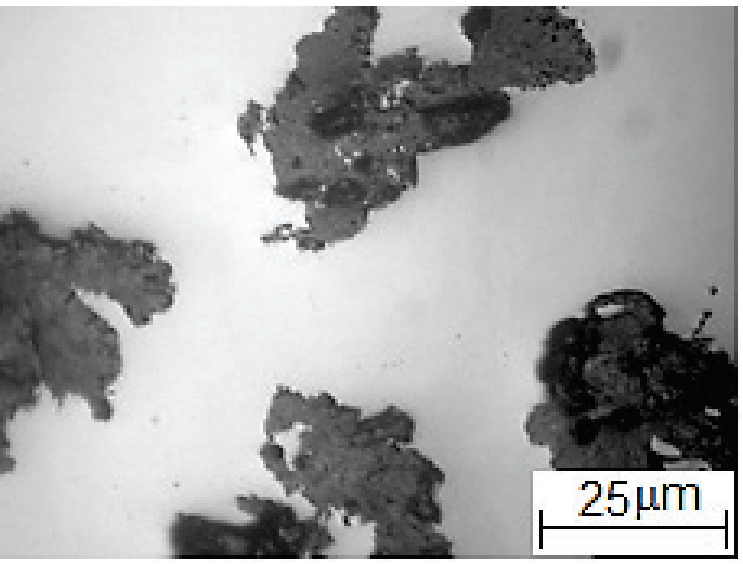

Figure 1 Structure of the working layer of cast iron roll: graphite eutectic

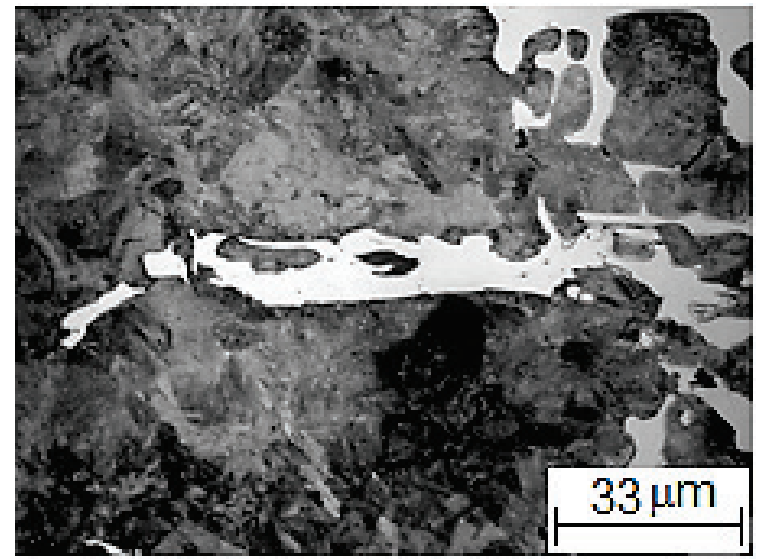

Figure 2 Colonies of Ledeburite, Graphite Eutectic, Pearlite Matrix, HNO3 Etching in working layer of cast iron roll

Impact strength of cast iron $\mathrm{KC}$ was determined with groove of notch dimensions of $10 \times 10 \times 55 \mathrm{~mm}$. For 
estimating the strength level during bending, $\sigma$ bars of $10 \times 10 \times 90 \mathrm{~mm}$ were used, and during tensile tests $\sigma_{\mathrm{B}}$ bars of $25 \mathrm{~mm}$ diameter were used with $50 \mathrm{~mm}$ gauge length. Hardness of cast iron bars, $H S D$, was defined according to Shore. For every structural component (cementite of ledeburite eutectic, pearlite, graphite) spectrum of statistical dimensions was counted as per Renyi formula [10]:

$$
D(q)=\frac{1}{q-1} \cdot \lim _{\delta \rightarrow \infty} \frac{\ln \sum_{i=1}^{N} p_{i}^{q}}{\ln \delta}
$$

where $p_{i}$ is hit probability of point that is located on the test specimen to the $i$ cell of square mesh with size $\delta$. Dimensions of spectrum $D_{0}, D_{1}, D_{2}, D_{\infty}, D_{-\infty}$ were calculated: $D_{0}$ is homogeneous fractal with $q=0$ (HausdorffBesikovitch dimension); $D_{1}$ is an informational dimension with $q=1$ (informational entropy) characterizing growth rate of the amount of information and showing growth of information, necessary for determining the point location on the test specimen as cell size $\delta$ tends to zero; $D_{2}$ is a correlation dimension with $q=2$, characterizing probability of occurrence in the same mesh cell of two points on the test specimen; $D_{\infty}$ is a dimension characterizing the most vacuum space in the test item (structure light segments); $D_{-\infty}$ is a dimension characterizing the most concentrated space (structure dark segments).

Fig. 3 shows the example of calculated spectrum of dimensionalities $D(q)$ of the structure, depending on interval of their variation $q$. In this case changes of index $q$ were specified within limits from -100 to 100 .

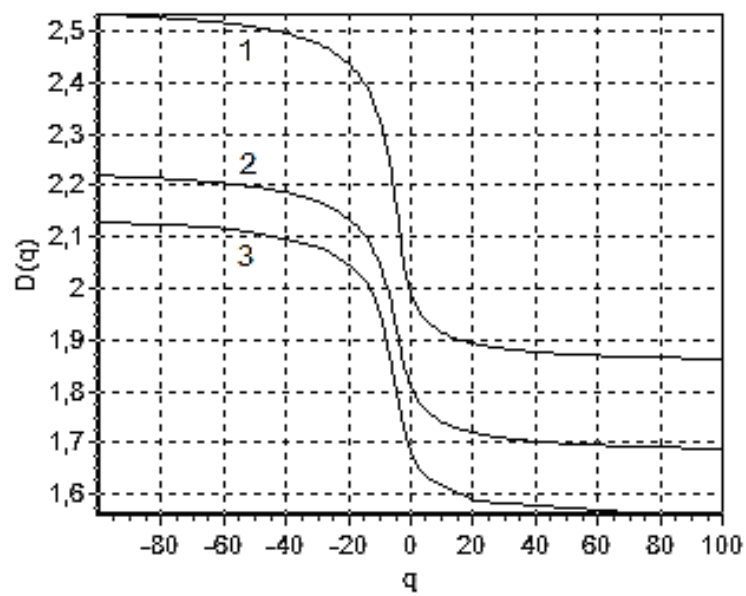

Figure 3 Spectrum of Dimensions of Cementite (1), Pearlite (2), Graphite (3)

\section{RESULTS AND DISCUSSION}

Method of material quality estimation with usage of multifractal theory comprises the following stages:

- Calculation of statistical dimensions' spectrum of structure elements according to Renyi formula.

- Determination of qualitative characteristics of the test material.
- Calculation of sensitivity of qualitative characteristics to statistical dimensions of structure elements.

- Description of relation between the most sensitive dimensions of the material structure elements and its qualitative characteristics.

For the materials science issues it is useful to study sensitivity of fractal or any other dimension of the material structure elements to changes of their qualitative characteristics through calculation of sensitivity coefficient $K_{i}(2)$ according to the method [11]:

$$
K_{i}=\frac{\left|Y_{i}-Y_{i+1}\right|}{\left|X_{i}-X_{i+1}\right|}
$$

The sensitivity will be maximal at those points of the structure where the maximum change in the metal properties is observed. It is shown in use [12] that sensitivity of the dimension's spectrum of the elements of ferrite and perlite structure of low-carbon low-alloy steel to mechanical properties is relatively high. This indicates that dimensional evaluation may be applied as an indicator of the material's quality characteristics.

Figs. 4-6 show the calculation results of sensitivity coefficients of cast iron mechanical properties $K_{i}$ to dimensional evaluation $D_{0}, D_{1}, D_{2}, D_{100}, D_{-100}$ of the structure calculated according to the formula (2).

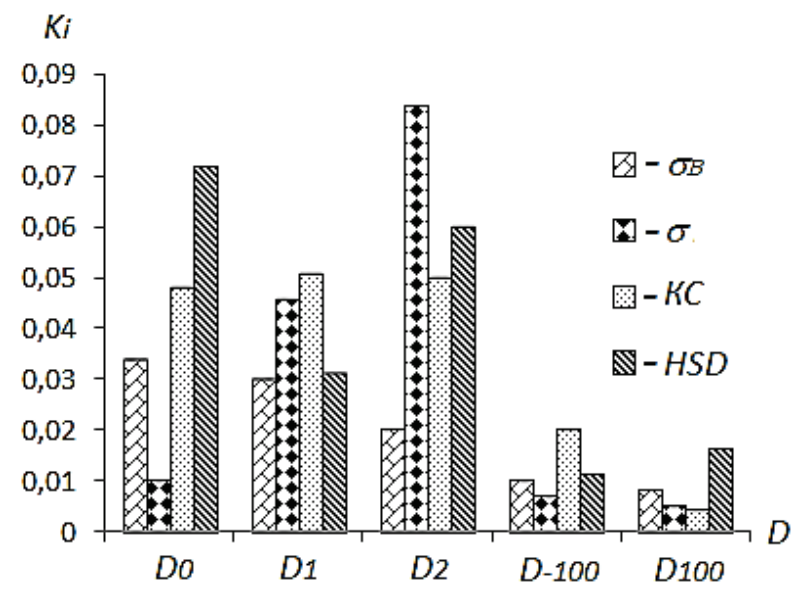

Figure 4 Sensitivity of Cast Iron Mechanical Properties to Dimensions of Graphite

Relatively high sensitivity indexes among those under consideration demonstrate strength characteristics $\left(\sigma_{\mathrm{B}}\right.$ and $\sigma$ ) and hardness $H S D$ to dimensions $D_{0}, D_{1}, D_{2}$ of cementite (Fig. 5) and graphite of spherical form (Fig. 4). This sensitivity results from influence of cementite $\mathrm{Fe}_{3} \mathrm{C}$ in cast iron alloy on increase in its hardness and strength, stabilization of pearlite, expansion in number of basic strengthening phase, wear resistance increase and reduce of plastic and antifriction properties. Upon the increase of graphite quantity in the cast iron structure, its strength, hardness and wear resistance reduce. Influence of graphite with spherical form on the mechanical properties is proven by sensitivity of these characteristics to dimensional 
evaluation (Fig. 4). For the ultimate strength sensitivity index to fractal dimension $D_{0}$ of cementite is 0.06 ; to informational dimension $D_{1}-0.07$ (Fig. 5). Sensitivity indexes for the ultimate bending strength $\sigma$ to cementite dimension $D_{0}$ and $D_{2}$ are 0.09 and 0.08 respectively (Fig. 5), and to graphite dimension $D_{2}$ is 0.084 (Fig. 4). Sensitivity coefficients between impact strength indexes $K C$, cementite dimensions $D_{0}, D_{2}$ (Fig. 5) and pearlite matrix $D_{2}$ (Fig. 6) are defined within 0.07 , which also confirms the influence of these structure elements on plastic properties of cast iron.

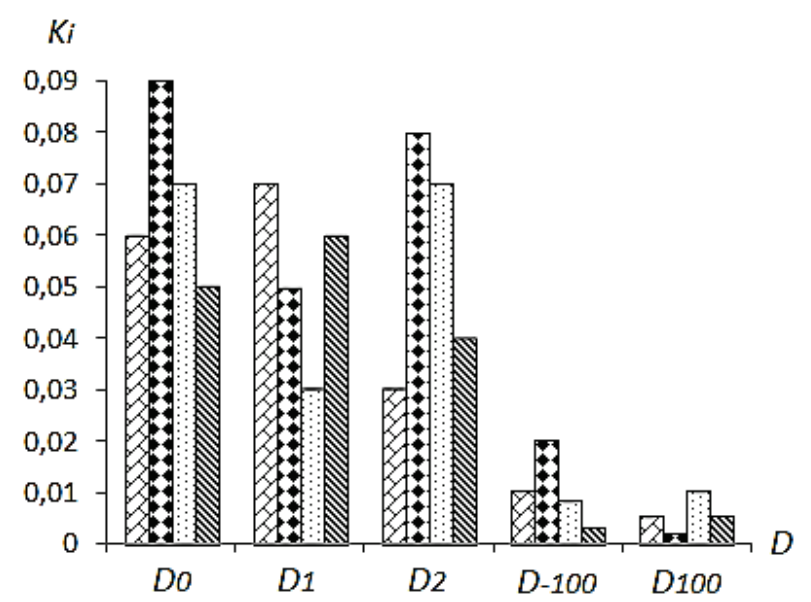

Figure 5 Sensitivity of Cast Iron Mechanical Properties to Dimensions of Cementite

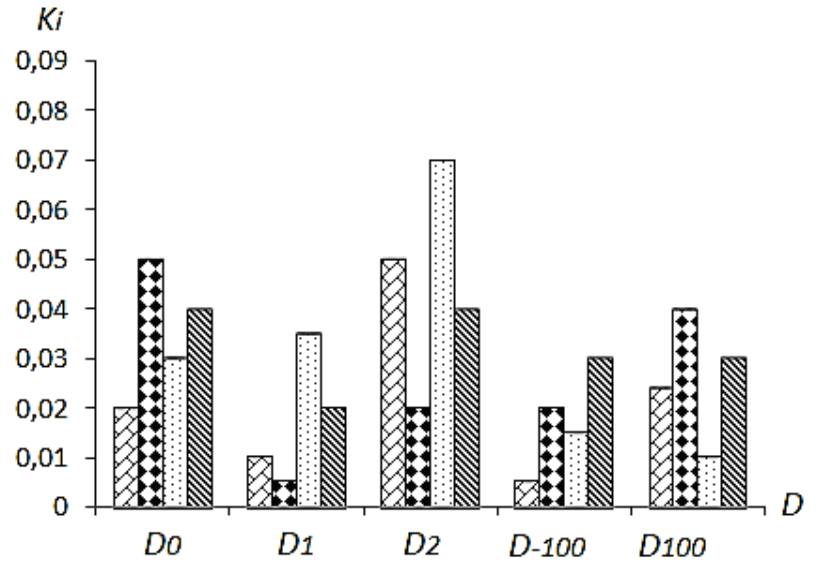

Figure 6 Sensitivity of Cast Iron Mechanical Properties to Dimensions of Pearlite

The above results indicate the influence of the structural elements form, expressed in fractal dimension, and their distribution in volume, expressed in the information and correlation dimensions on the mechanical properties of the metal.

Sensitivity indexes $\sigma_{\mathrm{B}}, \sigma, K C$ and $H S D$ to dimensions $D_{-100}$ and $D_{100}$ of cementite and graphite are relatively lower compared to dimensions $D_{0}, D_{1}, D_{2}$ (Figs. 4-6), which indicates small correlation between them.

Relations between the most sensitive dimensions of the cast iron structure elements and its mechanical properties (Fig. 7) as well as the relevant regression Eqs. (3)-(6) are shown below.

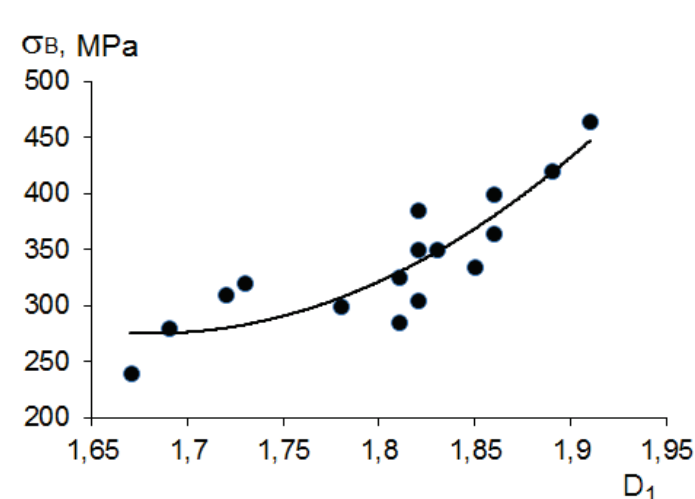

(a)

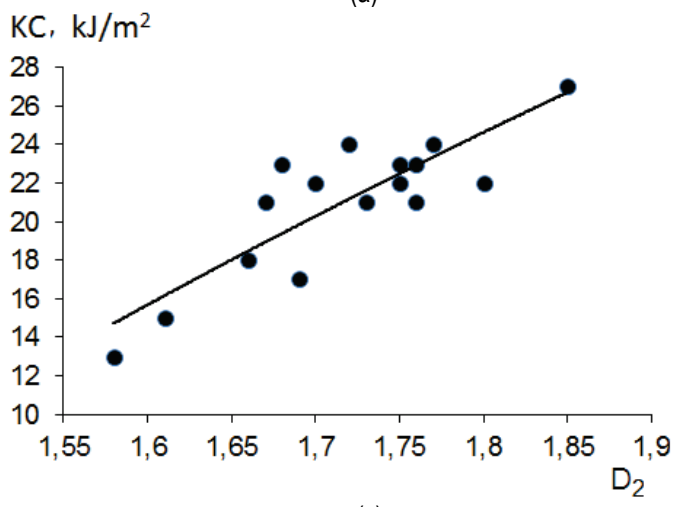

(c)

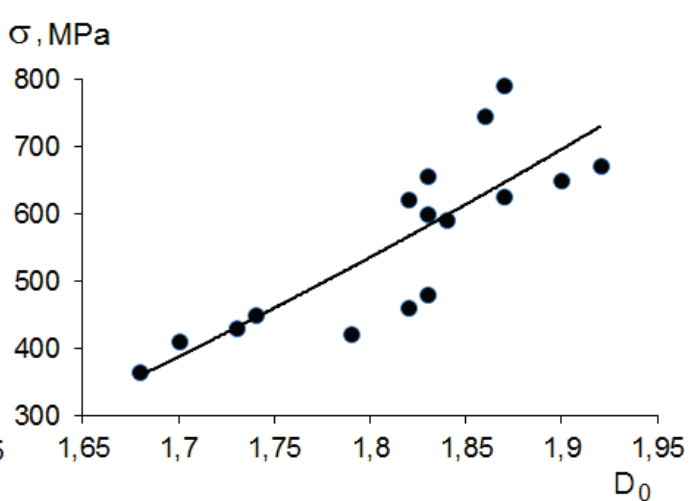

(b)

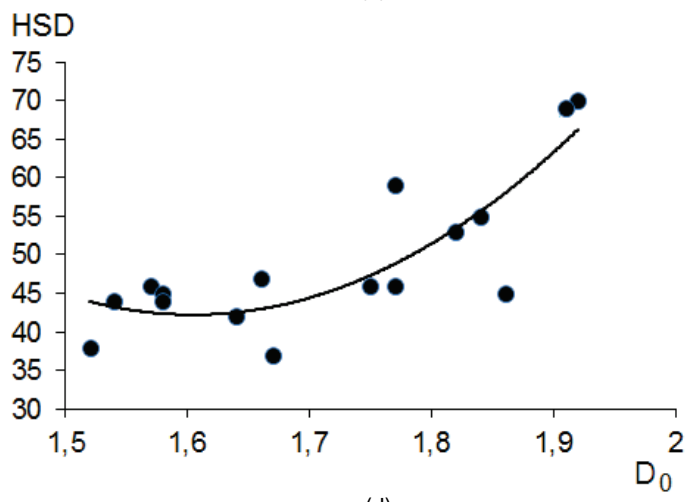

(d)

Figure 7 Dependence of Mechanical Properties on Cementite (a-c) and Graphite (d) dimensions 


$$
\begin{aligned}
& \sigma_{\mathrm{B}}=3284,30 \cdot D_{1}^{2}-11043 \cdot D_{1}+9558,40 \quad R^{2}=0,77 \\
& \sigma=1535,90 \cdot D_{0}-2226,80 R^{2}=0,68 \\
& K C=44,20 \cdot D_{2}-54,91 \quad R^{2}=0,72 \\
& H S D=241,76 \cdot D_{0}{ }^{2}-775,92 \cdot D_{0}+664,79 R^{2}=0,70
\end{aligned}
$$

Improvement of the cast iron mechanical properties $\sigma_{\mathrm{B}}$, $\sigma, K C$ (Figs. 7a-7c) is caused by influence of such technological factors as chemical composition, heat removal rate during cooling down of cast iron rolls. They influence not only the relation of structure elements but also their geometrical configuration, which is registered by the multifractal spectrum of Renyi dimensions.

Limits of graphite inclusions serve as microstress concentrators and increase of its contents weaken metal matrix of cast iron, which is indicative of influence on mechanical properties of cast iron either composition, sizes, distribution of graphite or form of such inclusions. The increase of hardness HSD from 35 to 70 units is connected with the increase of carbon content from 3.00 to $3.40 \%$. And growth of fractal dimension of graphite to 1.93 (Fig 6d) is caused by the change of its form (Fig. 1) to a spherical one because of increase of $\mathrm{Mg}$ inclusions from 0.035 to $0.056 \%$.

\section{CONCLUSION}

As a result of implementation of the cast iron quality estimation method, the following results have been obtained:

1) For the prediction of mechanical properties of rollfoundry iron, it is effectually to use dimensional evaluations $D_{0}, D_{1}, D_{2}$ of graphite and cementite, which is proven by the determined sensitivity between them.

2) Relatively high sensitivity among the indexes under consideration - ultimate strength, ultimate bending strength and impact strength - is recorded for dimensions $D_{0}, D_{1}, D_{2}$ of cementite, hardness sensitivity to fractal dimension $D_{0}$ of graphite.

3) Statistical dimensions of graphite and cementite $D_{-100}$, $D_{100}$ have relatively low sensitivity to the mechanical properties in the analyzed scale $(\times 300, \times 400)$.

4) The results indicate the influence of the structural elements form, expressed in fractal dimension, and their distribution in volume, expressed in the information and correlation dimensions on the mechanical properties of the metal.

The proposed method allows to evaluate the quality of cast iron on the basis of the dimensional values analysis characterizing the most sensitive elements of its structure and enables evaluation of mechanical properties of materials based on determination of their sensitivity to dimensions of structure elements from the multifractal Renyi spectrum.

\section{REFERENCES}

[1] Kos, Ž., Gotal Dmitrović, L., \& Klymenko, Ie. (2017). Developing a model of a strain (deformation) of a damaged reinforced 150 concrete pillar in relation to a linear load capacity. Tehnički glasnik - Technical Journal, 11(4), 150154.

[2] Aniskin, A., Orešković, M., \& Kozina, G. (2017). The effects of particles orientation on lateral pressure within the confined vertical walls. Tehnički vjesnik, 24(4), 1349-1253. https://doi.org/10.17559/TV-20160826121746

[3] Mishutn, A., Kroviakov, S., Pishev, O., \& Soldo, B. (2017). Modified expanded clay light weight concretes for thinwalled reinforced concrete floating structures. Tehnički glasnik - Technical Journal, 11(3), 121-124.

[4] Kroviakov, S. \& Mishutn, A. (2017). Production technology of modified expanded clay lightweight concrete for floating structures. The Scientific Journal of Cihan University Sulaimanyia, 1(4), 2-10.

[5] Dubrov, Yu., Bol'shakov, V., \& Volchuk, V. (2015). Paths to Identification of Periodic Multicriteria Technologies. Saarbrucken, Deutschland: Palmarium Academic Publishing. (in Russian)

[6] Mandelbrot, B. B. (1982). The Fractal Geometry of Nature. New York-San Francisco: Freeman.

[7] Bolshakov V., Volchuk V., Dubrov Yu. (2016). Fractals and properties of materials. Saarbrucken, Deutschland: Lambert Academic Publishing.

[8] Volchuk, V. M. (2017). On the Application of Fractal Formalism for Ranging Criteria of Quality of Multiparametric Technologies. Metallofizika $i$ Noveishie Tekhnologii, International Scientific and Technical Journal of the Institute of Metal Physics. G.V. Kurdyumov National Academy of Sciences of Ukraine, 39(7), 949-957. (in Russian) https://doi.org/10.15407/mfint.39.07.0949

[9] Bolshakov, V. I.; Volchuk, V. M.; \& Dubrov, Yu. I. (2016). Fundamentals of fractal modeling. Kyiv, Ukraine: $\mathrm{PH}$ "Akademperiodyka" National Academy of Sciences of Ukraine.

[10] Rényi, A. (1970). Probability Theory. Amsterdam, Netherlands: North-Holland.

[11] Bolshakov, V. I. \& Dubrov, Yu. I. (2002). An estimate of the applicability of fractal geometry to describe the language of qualitative transformation of materials. Journal of Reports of the National Academy of Sciences of Ukraine, 4, 116-121. (in Russian)

[12] Volchuk, V. M. (2015). Determining the sensitivity of the multifractal characteristics of metals, Bulletin of Prydniprovs'ka State Academy of Civil Engineering and Architecture, Ukrainian. Journal of Technical Sciences, Constructions and Architectures, 12, 10-14. (in Russian) 
Authors' contacts:

Volodymyr VOLCHUK, PhD, Assoc. Prof.

Prydniprovs'ka State Academy of Civil Engineering and Architecture

Department of materials science,

24a Chernyshevskyst., Dnipro, Ukraine

volchuky@gmail.com

levgenii KLYMENKO, PhD, Full Professor, vice-rector

Odessa State Academy of Civil Engineering and Architecture,

4 Didrihsona st., Odessa, Ukraine

klimenkoew57@gmail.com

Sergii KROVIAKOV, PhD, Assist. Prof.

Odessa State Academy of Civil Engineering and Architecture,

4 Didrihsona st., Odessa, Ukraine

skrovyakov@ukr.net

Matija OREŠKOVIĆ, PhD

Sveučilište Sjever, Sveučilišni centar Varaždin, Odjel za graditeljstvo Jurja Križanića 31b, 42000 Varaždin, Croatia

moreskovic@unin.hr 